JURNAL RUPA VOL 4 NO 2 DECEMBER 2019

DOI address: http://doi.org/ 10.25124/rupa.v4i2.1433

\title{
Elemen Budaya Melayu Pada Rumah Tjong A Fie di Medan
}

\author{
Rudiansyah* \\ Fakultas IImu Budaya, Universitas Sumatera Utara, Medan, Indonesia
}

\begin{abstract}
The title is 'The elements of Malay cultural at Tjong A Fie's house in Medan' is selected as the title of the article with the purpose of assessing and understanding the acculturation that was discovered on the buildings with Chinese style in Medan City. This research was focused on the objects of Tjong A Fie's house. This research used John W. Berry's acculturation theory; while the method that is used is the qualitative descriptive method. An acculturation is a prosess that happens when one group of people with some kind of culture confronts the elements of some other culture. From this comes into being the change of the origin cultures, yet these two cultures have not lost the elements of their own cultures. The acculturation can be seen on part of Tjong A Fie's house like the gold color that was used dominatedly, the pictures on the cloth and the Malay special window shapes.
\end{abstract}

Keywords: Malay culture, acculturation, Chinese house, Tjong A Fie, Medan

$\begin{array}{ll}\text { Rudiansyah } & \\ \text { Email } & \text { : rudiansyah@163.com } \\ \text { Address } & \text { : Fakultas Ilmu Budaya, Universitas Sumatera Utara } \\ & \text { Jalan Universitas No.19 Medan-Sumut } 20155\end{array}$




\section{Elemen Budaya Melayu Pada Rumah Tjong A Fie di Medan}

Rudiansyah

\section{PENDAHULUAN}

Untuk bisa melihat arsitektur Tiongkok di suatu kota, biasanya harus melihat di daerah Pecinannya. Namun, untuk menentukan tempat bekas daerah Pecinan pada suatu kota tidaklah mudah. Hal ini selain karena perkembangan kota yang sangat cepat, juga karena biasanya daerah Pecinan tidak terdokumentasi dengan baik. Daerah Pecinan beserta peraturannya sudah dihapus sejak tahun 1900-an, meskipun penghapusan peraturan secara resmi baru dilakukan pada tahun 1920 [1]. Hampir seluruh kota di Indonesia memiliki kawasan Pecinan yang memiliki fungsi sebagai kawasan sentral perdagangan dan permukiman bagi orang-orang Tiongkok. Pengamatan juga diperkuat dengan adanya rumah tinggal, klenteng/vihara, sekolah dan peninggalan lainnya di daerah tersebut, yang tidak hanya berfungsi sebagai tempat ibadah saja tetapi juga memiliki peran yang besar dalam kehidupan komunitas Tiongkok di masa lampau. Hal ini sesuai dengan yang diungkapkan bahwa, "sebuah wilayah pada masa kolonial ditinjau dari tata ruang dan bangunannya terdiri atas alun-alun, tempat ibadah, kantor pemerintahan, rumah, penjara, dan kampung Tiongkok" [1]. Sampai saat ini di kawasan Pecinan masih berdiri bangunan-bangunan dengan aplikasi budaya Tiongkok maupun akulturasi budaya Tiongkok dengan budaya sekitar.

Berbicara tentang Pecinan, Sumatera Utara juga menyimpan banyak peninggalan yang tidak terlepas dari aspek historisnya yang merujuk pada kawasan situs kota Tiongkok yakni Kesawan kota Medan yang ramai dikunjungi pada permulaan abad ke-12 hingga awal abad ke-14. Pada masa itu, berdasarkan bukti-bukti arkeologisnya (archeological evidence) diketahui cenderung merujuk pada era Dinasti Sung, Yuan dan Ming di Tiongkok. Demikian pula temuan-temuan tersebut menunjukkan bahwa komunitas pedagang yang berasal dari mancanegara seperti Tiongkok, Johor, Jawa, Burma, Thailand pernah singgah di Sumatra Utara.

Situs kawasan Pecinan di daerah Kesawan merupakan cikal bakal terbentuknya Kota Medan sekarang yang berasal dari permulaan abad ke-12. Hal ini ditunjukkan oleh banyaknya peninggalan atau bukti arkeologis yang tertuju pada satu era yakni sejak abad ke-12 hingga awal abad ke-14, seperti fragmen earthenware (tembikar), fragmen porselen (keramik), koin (mata uang), pecahan kaca, batu bata berfragmen candi, arca, tulang belulang, atau bahkan sisa-sisa perahu tua (ships ruins).

Adanya perbedaan budaya antara masyarakat setempat dengan masyarakat pendatang, memungkinkan terwujudnya perpaduan budaya keduanya (culture acculturation). Perbedaan kebudayaan masyarakat setempat dengan masyarakat pendatang membuat rumah tinggal orang Tionghoa memiliki ciri khas tertentu. Berbagai elemen dan komponen rumah tinggal yang di bangun melambangkan akulturasi budaya serta dapat memberi cerita kehidupan pada masa itu. Selanjutnya dipahami bahwa unsur akulturasi pada bangunan tersebut mempunyai arti yang lebih luas, dimana rumah tinggal orang Tionghoa tersebut menjadi perwakilan dari kosmos, masyarakat, atau tubuh manusia [2].

Salah satu keunikan dan keistimewaan bangunan bergaya Tiongkok sebagai Pusaka Indonesia yang masih terlihat dan dapat dinikmati sampai saat ini yaitu bangunan rumah Tjong A Fie, bangunan ini memiliki ciri khas dengan kawasan Pecinan yang ada di daerah lain. Unsur akulturasi pada bangunan rumah Tjong A Fie di daerah Kesawan Kota Medan 
merupakan hasil perpaduan antara budaya Tiongkok bercampur dengan budaya Melayu. Perpaduan budaya tersebut terlihat pada desain dan ornamen serta arsitektur bangunan berupa rumah deret, rumah toko maupun rumah tinggal dimana bentuk atapnya memiliki arsitektur Tiongkok tetapi pada detail-detail fasade terdapat keberagaman budaya yang mempengaruhinya.

Arsitektur bangunan Tjong A Fie juga tidak terlepas dari pengaruh kehidupan sosialbudaya yang merupakan hasil perpaduan dari berbagai kebudayaan yaitu budaya Tiongkok yang kemudian berpadu dengan budaya Melayu. Hal ini membuktikan bahwa bangunan rumah Tjong A Fie menampilkan perpaduan budaya (acculturation) antara masyarakat Tiongkok dengan Melayu. Kekhasan ini diperkuat pula dengan adanya desain serta ornamen khas dari budaya melayu yang terdapat pada rumah Tjong A Fie di Kota Medan.

\section{HASIL DAN PEMBAHASAN}

Pembahasan yang akan dilakukan dalam penelitian ini adalah tentang unsur akulturasi budaya pada rumah Tjong A Fie melalui teori akulturasi oleh John W. Berry. Penulis memilih teori akulturasi, karena dengan teori ini penulis dapat membedah dan mengetahui unsur budaya Melayu yang terkandung pada bangunan rumah Tjong A Fie di kota Medan.

\section{Karakteristik Arsitektur Melayu Deli}

Seperti halnya pada arsitektur lainnya, arsitektur melayu juga memperhatikan pengaruh iklim dalam proses pembangunan rumah, hal terlihat pada bentuk istana Maimun. Posisi lantai di atas tanah merupakan cara untuk mengurangi kelembaban serta memberikan sirkulasi udara yang baik. Arsitektur Melayu Deli dapat dikatakan arsitektur vernacular yang berasal dari kebudayaan rumpun masyarakat Melayu. Bahan bangunan yang digunakan pada bangunan Melayu Deli berasal dari daerah setempat, demikian juga sistem struktur dan konstruksinya. Bahan alami yang digunakan dalam pembangunannya yaitu nipah, nambia, anak kayu, batang nibung, batang pinang, dan bambu [3].

Penyusunan ruang dan komponen serta unit bangunan sangat kuat dipengaruhi oleh faktor adat istiadat dan agama seperti paras lantai, pintu masuk utama, hiasan, dan orientasi. Dengan level yang tinggi digunakan sebagai ruang untuk beribadah dan juga digunakan untuk keramaian dan tempat penyelenggaraan apabila ada yang meninggal dunia. Karakteristik bangunan Melayu Deli yakni dibangun pada tiang yang tingginya sekitar 0,82 meter. Dinding bangunan Melayu Deli umumnya terbuat dari papan yang dipasang miring, vertikal, maupun bersilang dipenuhi hiasan ukiran sebagai ornamen. Bagian atas dan kanan kiri pintu diukir dengan motif ukiran berbentuk bunga. Pintu dan tangga umumnya terletak di bagian depan bangunan. Ukuran jendela yang terdapat pada bangunan rumah Tjong A Fie sama dengan ukuran jendela yang terdapat pada istana maimun dan merupakan salah satu karakteristik bangunan Melayu Deli. Penggunaan jendela yang banyak bertujuan untuk memberi udara dan cahaya bagi penghuni bangunan. Ukiran-ukiran pada dinding dan tiang dominan menggunakan bentuk bunga, alam, kaligrafi, hewan, daun, buah, serta suluran-suluran [3].

\section{Ornamen Arsitektur Melayu Deli}

Adapun jenis ornamen Melayu Deli yang terdapat pada bangunan rumah Tjong A Fie yaitu : ornamen tumbuh-tumbuhan, pucuk rebung, lebah bergantung, bintang, sinar matahari pagi, dan terali biola. Lebih rinci ulasannya adalah sebagai berikut: 
Ornamen Bunga Manggis

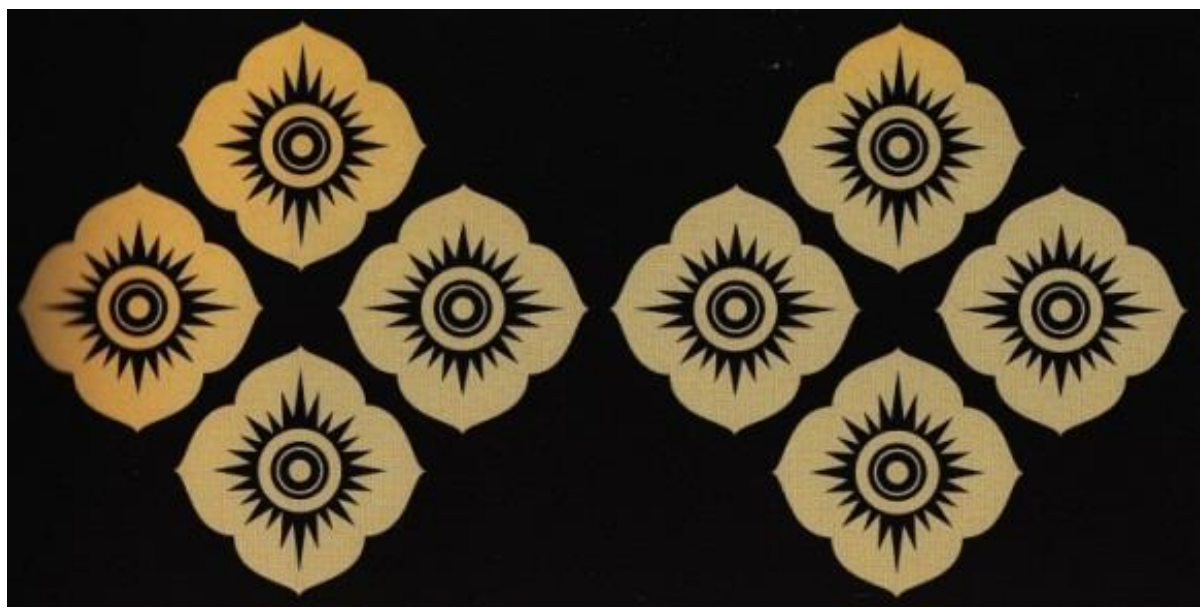

Gambar 1 Ornamen Bunga Manggis (Foto: Ayu Kartini)

Ornamen Bunga Manggis ini disebut tumpak manggis. Bunga Manggis ini merupakan lambang keharmonisan yang diterapkan pada rumah Tjong A Fie.

Ornamen Bunga Cengkih

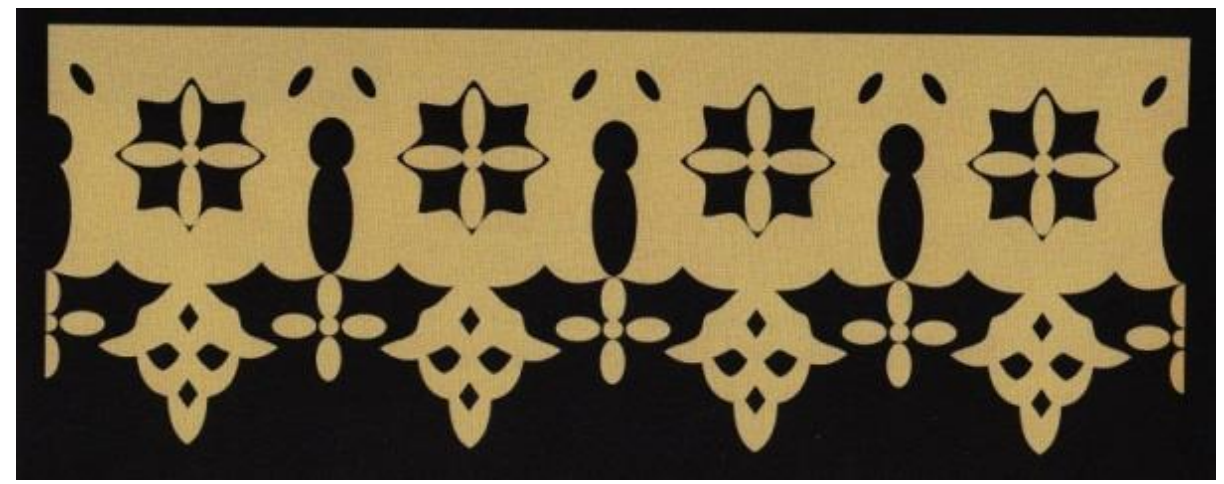

Gambar 2 Ornamen Bunga Cengkih (Foto: Ayu Kartini)

Bunga Cengkih dipercaya sebagai lambang kemegahan, sehingga Tjong A Fie menerapkannya pada bangunan rumah tinggal.

Ornamen Roda Bunga

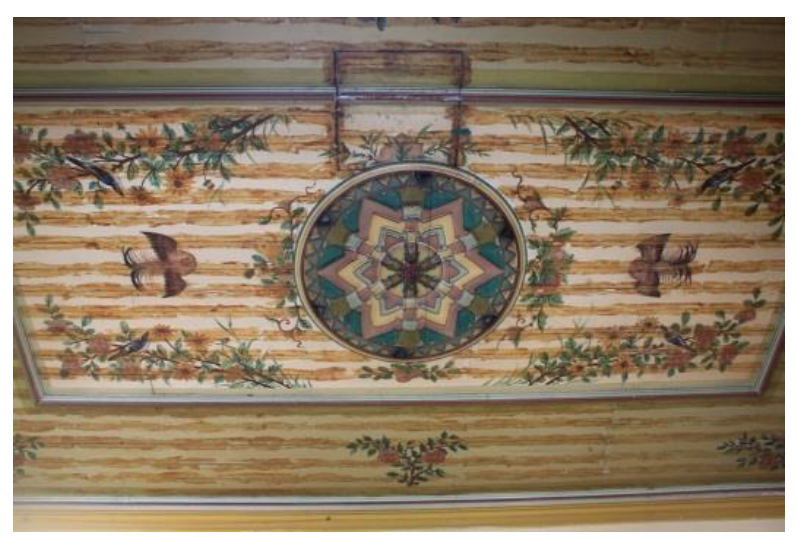

Gambar 3 Ornamen Roda Bunga (Foto: Rudiansyah) 
Ornamen roda bunga berbentuk bunga-bungaan, yang berfungsi sebagai keindahan. Selain itu, ragam hias roda bunga memiliki bentuk setengah lingkaran yang dibuat dari tangkupan bunga. Pada bagian atas disudut kanan dan kiri diisi dengan hiasan berbentuk mahkota yang terbuat dari sulur-suluran daun dan bunga.

\section{Pucuk Rebung}
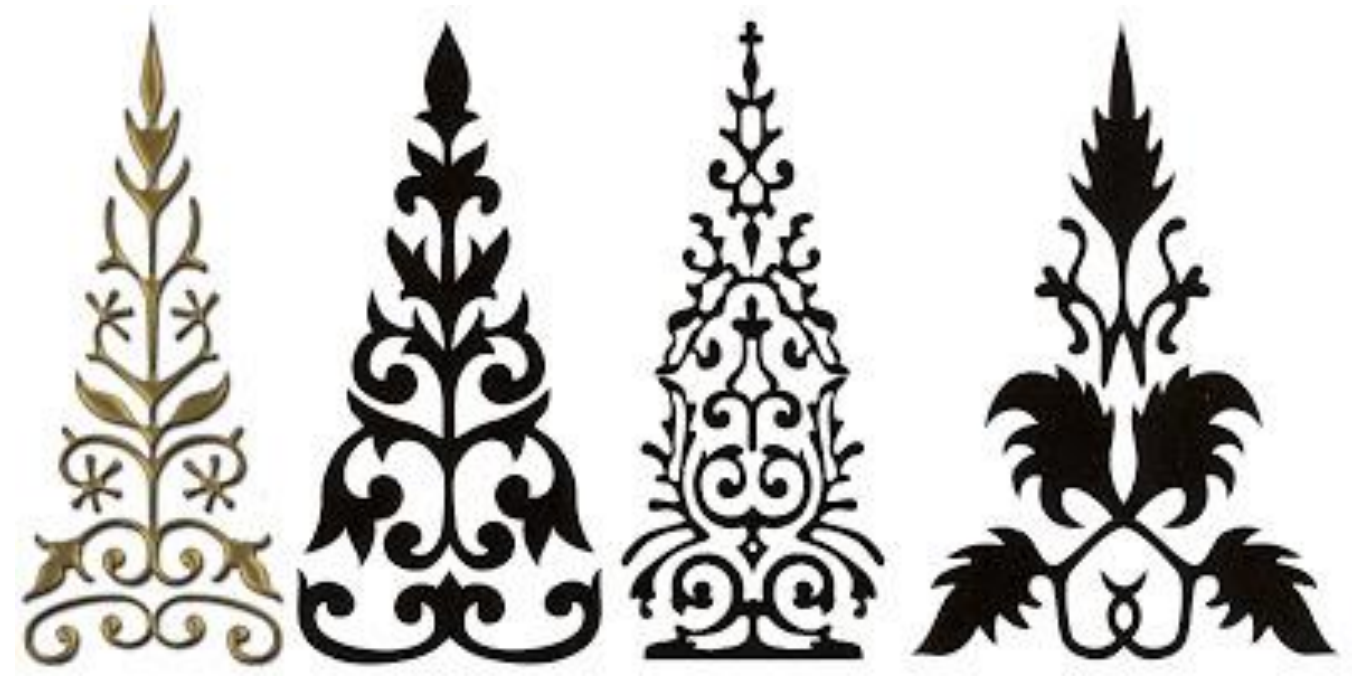

Gambar 4 Ornamen Pucuk Rebung (Sumber: Ayu Kartini, 2014)

Pucuk rebung memiliki bentuk segitiga dengan terdapat garis-garis lengkung dan lurus didalamnya. Motif ini melambangkan kebahagiaan dalam kehidupan.

Lebah Bergantung

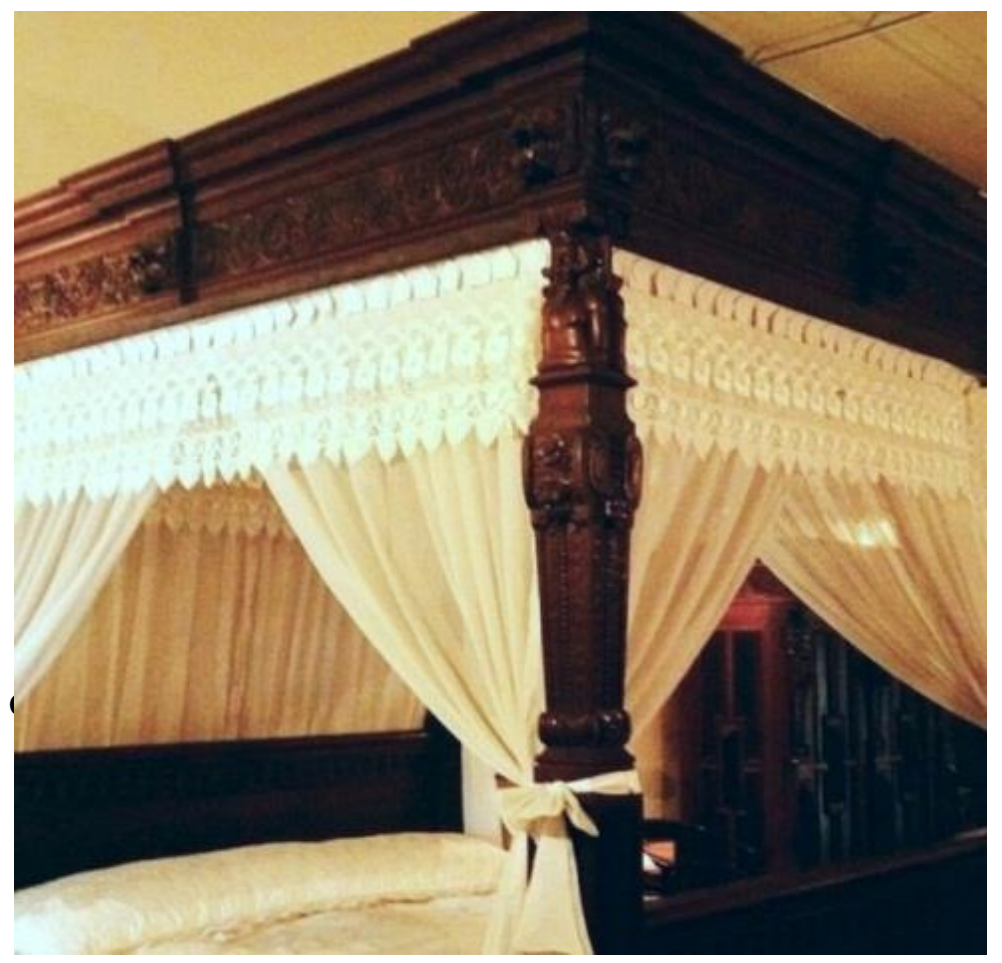

Gambar 5 Ornamen Lebah Bergantung 
Ornamen ini memiliki bentuk yang menyerupai sarang lebah yang bergantung pada dahan kayu. Ditambah variasi dengan lekukan dan bunga-bunga yang berbentuk memanjang. Ukiran lebah bergantung terletak pada lisplang dan sebagai hiasan yang terdapat pada bagian bawah bidang yang memanjang.

Bintang

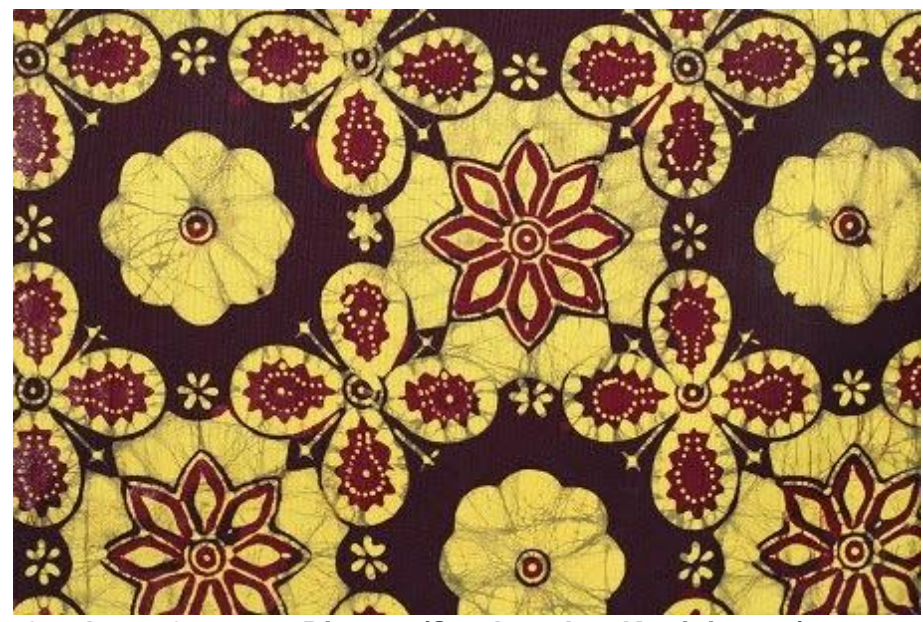

Gambar 6 Ornamen Bintang (Sumber: Ayu Kartini, 2014)

Ornamen ini bentuknya menyerupai bintang yang bersinar. Motif bintang bermakna kekuasaan Tuhan, dan sumber sinar dalam kehidupan manusia.

Ornamen Sinar Matahari Pagi

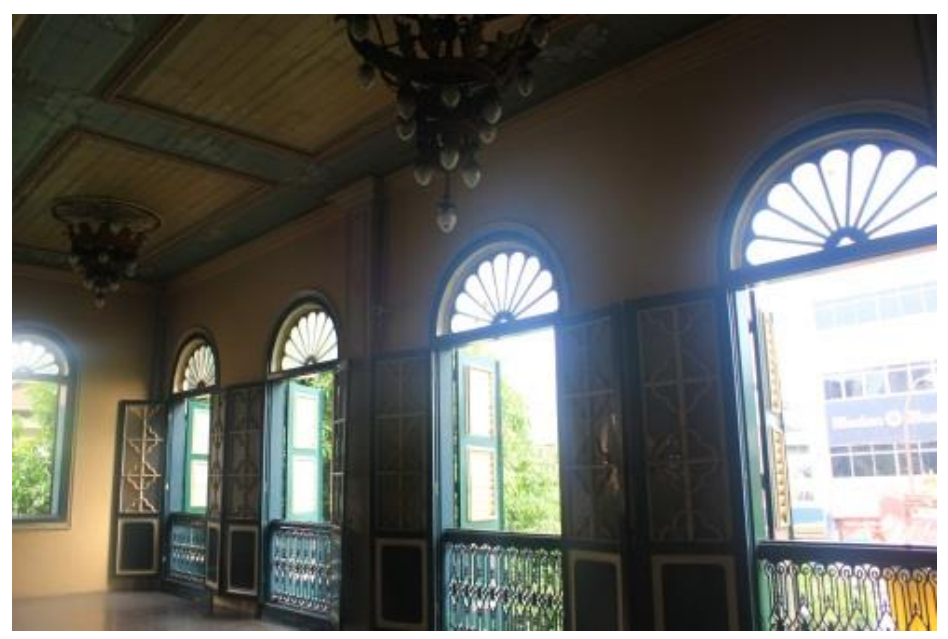

Gambar 4 Ornamen Sinar Matahari Pagi (Sumber: Rudiansyah, 2018)

Ornamen sinar matahari pagi yang terdapat pada bangunan rumah Tjong A Fie di terapkan pada kasa jendela atau kasa pintu ruangan dalam rumah. 


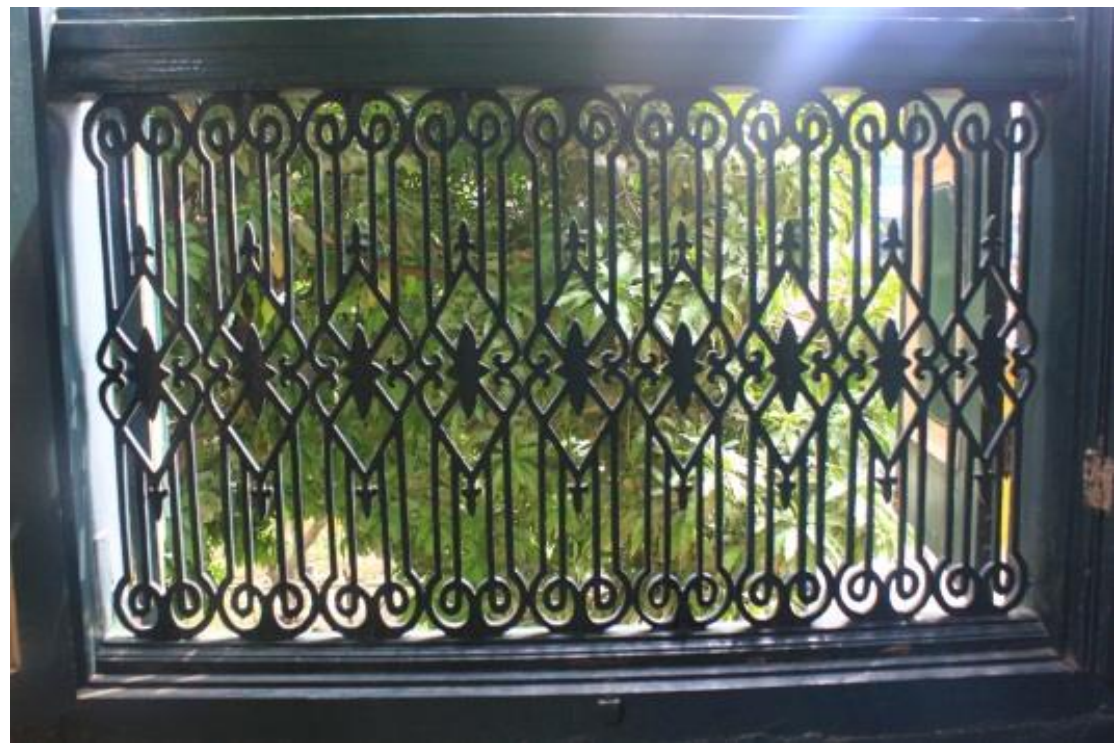

Gambar 5 Ornamen Terali Biola (Sumber: Rudiansyah, 2018)

Ornamen ini memiliki bentuk lekuk-lekuk tebukan yang mirip dengan bentuk biola, terbuat dari kepingan papan yang diukir lalu disatukan. Berfungsi sebagai pagar dan untuk memperindah beranda.

\section{KESIMPULAN}

Dari hasil analisa yang telah dilakukan dapat disimpulkan bahwa, pada bangunan rumah Tjong A Fie di Kota Medan terdapat unsur-unsur arsitektur budaya Melayu. Rumah Tjong A Fie merupakan salah satu bangunan hasil akulturasi yang ada di daerah Kesawan kota Medan. Unsur arsitektur Melayu mendominasi pada bangunan berupa ornamen. Bangunan ini menjadi bukti bahwa arsitektur Tiongkok dapat di sandingkan dengan arsitektur Melayu. Oleh karena itu sangat disayangkan jika pada abad 21 ini, seiring dengan pesatnya perkembangan penduduk, bangunan hasil akulturasi yang ada di kota Medan seperti ini masih kurang dilestarikan sebagaimana mestinya.

Setelah melalui beberapa tahap penelitian terhadap bangunan rumah Tjong A Fie di daerah Kesawan kota Medan, serta dilakukannya pengamatan ornamental dan struktural terhadap bangunan Melayu yang ada di kota Medan, maka diperoleh hasil kesimpulan yang menjawab permasalan dalam penelitian ini. Masalah pertama yang harus dijawab adalah bagaimana ornamental dan struktural yang diterapkan pada bangunan rumah Tjong A Fie di Kota Medan. Adapun unsur-unsur yang diteliti adalah unsur arsitektur dan unsur ornamental sebagai unsur arsitektur yang dapat dijadikan indikator adanya percampuran dari budaya Melayu. Masalah kedua adalah menjelaskan bagian-bagian yang termasuk kedalam unsur arsitektur Melayu. Hasil yang diperoleh dari deskripsi dan analisa pada bangunan rumah Tjong A Fie di kota Medan dapat dikatakan bahwa unsur arsitektur lokal yang terlihat pada bangunan rumah Tjong A Fie menunjukkan ciri bangunan Melayu Deli.

Unsur budaya Melayu dapat dilihat dari beberapa ornamen khas Melayu seperti, ornamen bunga manggis, bunga cengkih, roda bunga, pucuk rebung, lebah bergantung, bintang, sinar matahari pagi dan terali biola. Beberapa ornamen bahkan memiliki makna yang dipercaya oleh masyarakat Melayu dapat mendatangkan aurah positif/kebaikan. Arsitektur bangunan rumah Tjong A Fie juga memperlihatkan adanya penyesuaian dengan iklim tropis di Indonesia. Salah satu ciri iklim tropis adalah curah hujan yang tinggi. 
Penyesuaian bangunan terhadap curah hujan yang tinggi ini dapat dilihat pada bentuk atap yang dibuat miring agar air hujan dapat langsung turun kebawah. Penggunaan genteng sebagai bahan penutup atap juga dimaksudkan untuk memperlambat penerusan panas ke dalam rumah Tjong A Fie. Bentuk penyesuaian lain dapat terlihat pada orientasi bangunan rumah Tjong A Fie, yaitu utara-selatan. Dimana jika fasade bangunan berada di bagian selatan atau utara maka akan menerima lebih sedikit panas dan cahaya matahari.

\section{DAFTAR PUSTAKA}

[1]. Handinoto. 1998. Arsitektur Gaya Indo Eropa Tahun 1920an di Indonesia. Surabaya. Universitas Kristen Petra;

[2]. Perkins D. 1998. Encyclopedia of China: History and Culture. Chicago. Routledge: 684 p.

[3]. Sinar TL. 1994. Sejarah Deli Serdang. Lubuk Pakam: Penerbit Pemerintah Daerah Tingkat II Deli Serdang; 